Published as: Liu, X. \& Derudder, B. (2013) Analyzing urban networks through the lens of corporate networks: a critical review. Cities, 31, 430-437.

\title{
Analyzing urban networks through the lens of corporate networks: a critical review
}

\begin{abstract}
This paper provides a critical review of three major empirical models for approximating urban networks based on corporate networks: the ownership linkage model, the interlocking network model, and the two-mode network model. We review the assumptions, implementations, strengths and shortcomings of these models through pedagogic examples. Based on this review, we suggest that (1) there exists a need to synthesize analytical results from different models; (2) calibration approaches are needed to improve the falsifiability of modeling results; and (3) the two-mode network approach seems to be the most promising approach for analyzing urban networks through corporate networks as it is capable of assessing cities and firms simultaneously, as well as modeling the underlying network formation process.
\end{abstract}

\section{Keywords}

Corporate networks, ownership linkages, interlocking network model, two-mode networks 


\section{Introduction}

The purpose of this paper is to present a critical review of the main ways in which researchers have used information on corporate networks to attain insight into the geographies of urban networks. The idea that corporations are key agents in the formation of urban systems is of course a longstanding one in research on urban studies. For instance, continuing a long and fruitful tradition of 'national urban systems' research, Tonts and Taylor (2011) recently examined the Australian urban system based on an analysis of the urban geographies of corporate headquarters, giving consideration to their location, control of capital, and performance. Meanwhile, at the global scale, Taylor and Csomos (2012) present a similar reading of 'world cities' by gauging the quantity of revenue generated in cities by multinational firms headquartered there. The multifaceted and multiscalar impact of firm location on urban systems obviously also 'works' in the opposite direction: just as urban systems are shaped by the locational behavior of firms, urban systems shape the spatial distribution of corporations as the dispersion and development of firms are affected by the size and functional specialization of cities, as well as the cities' positions within the urban system (Pred, 1977; Friedland et al., 1990; Beaverstock et al., 2002).

Within the vast literature on 'urban systems', the notion of 'urban networks' has increasingly become an organizing paradigm (e.g. Camagni, 1993; Yates, 1997; Castells, 2001). In its most basic guise, the urban network paradigm departs from some of the 'traditional' approaches in that it no longer predominantly focuses on 'characteristics' of cities in and by themselves (e.g. using the number of headquarters to formulate the urban system as in Goddard and Smith, 1978; see however, Taaffe, 1962). Indeed, from roughly the early 1990s onwards, we see a rising interest in describing urban systems through the analytical lens of flows between cities. A seminal contribution in this regard is a paper by Mitchelson and Wheeler (1994), who introduced the idea of using data on information movements between cities to reveal the geographies of the US urban system. In the years following this paper, using data on connections between cities to describe and analyze urban systems became increasingly popular (Taylor, 1997). This was in turn fuelled by the interest in 'globalization', emphasizing the relevance of boundarycrossing linkages involving people, capital, information, services, and goods (Holton, 2008). It was thereby often argued that these transnational flows have altered the spatial configuration of the global economy as a whole, with transnational intercity relations at its core (Castells, 2001).

The urban network paradigm emphasizes the bearing of external relations of cities when describing and analyzing urban systems ${ }^{1}$. The key empirical consequence is that urban systems are specified and analyzed as of a set of objects (cities) where some pairs are connected by links of varying strength (city relations) ${ }^{2}$. For the sake of

\footnotetext{
${ }^{1}$ This shift is, of course, part of a broader paradigmatic shift towards 'relational geographies' in human geography in general (Massey et al. 1999) and urban geography in particular (Jacobs, 2011).

${ }^{2}$ In our context, urban networks and urban systems are used interchangeably, as there is one urban network behind every urban system, defining the external relations between cities.
} 
this paper, the key point is that the city/firm-nexus has thus been re-specified away from an analysis of cities as mere 'collections' of firms (cf. Tonts and Taylor, 2011) to an analysis of cities as nodes in the 'network structures' of firms (cf. Taylor et al., 2009).

In practice, however, the actual devising of datasets as well as their subsequent analysis has taken on very different forms. Although this variegation points to the overall vitality of this literature, it also engenders the potential problem of a cacophony that makes it hard to fruitfully liken results from different empirical analyses of urban networks. To help ease some of the fuzziness that is emerging within this literature, in this paper we present a critical overview of the different empirical models that have been implemented in the literature analyzing urban networks through the lens of corporate networks. Cast in this way, this contribution can also be seen as a follow-up to a paper by Derudder (2006), in which the data sources used in urban network research were reviewed.

To keep our discussion manageable, we will predominantly focus on network models that been devised in the context of 'world city network' (WCN) research, which has arguably one of the most vibrant strands of research in this context. However, most of the observations developed here can also be applied to other scales, including regional/national urban networks (Bassens et al., 2010) and the spatial organization of polycentric megacity-regions (Hall and Pain, 2006).

\section{Starting point: a two-mode city-by-firm network}

In spite of all the 'network talk', the starting point for all corporate-based analyses of urban networks is a city-by-firm data matrix rather than a city-to-city adjacency matrix proper (see Nordlund 2004; Liu and Derudder, 2012). The WCN analyses of the Globalization and World Cities (GaWC) research network, for instance, start from a city-by-firm matrix that contains data on the location strategies of producer service firms in cities across the settled world. Similarly, city-by-firm datasets are collected as intermediate products in WCN studies that focus on the global command and control of multinational enterprises (Alderson and Beckfield, 2006; Wall 2009).

Although only seldom explicitly acknowledged, this city-by-firm matrix can in itself be regarded as a network, i.e., a so-called two-mode or bipartite network (Neal, 2008; Liu and Derudder, 2012). In contrast to - probably more well known - onemode networks, where actors are directly interlinked (e.g. cities connected by airline flows), a two-mode network is characterized by connections between two separate sets of nodes (cities and firms, respectively). In principle, there is no direct linkage within the same set of nodes (i.e. between cities or between firms): researchers simply know which firms are in what cities, and which cities house what firms. However, it is possible to infer one-mode networks from the two-mode dataset by applying a 'projection' function, which in the case of the city-to-city-matrix essentially represents a methodical guesstimate of how different parts of the firm 'interact' across space (Latapy et al., 2008). As we will see, applying such a projection 
function is neither necessary nor by definition the best approach, but it has nonetheless been the dominant way of handling the city-by-firm matrix. Referring back to the GaWC example, for instance, it can be seen that in most cases their cityby-firm data matrix is transformed into an inter-city matrix by applying what has been termed 'the interlocking network model' (Taylor, 2001, 2004). Nordlund (2004) has dismissively dubbed this GaWC projection function 'turning apples into oranges'; however, although this rightly hints at potential problems with projection functions, it should be noted that this approach is widely acknowledged and applied in network analysis, and cannot be dismissed out of hand (Borgatti and Everett, 1997).

The bipartite city-by-firm matrix comes in different forms, whereby the major difference lies in the level of measurement of firm presence: (1) dichotomized, only distinguishing between a firm's presence or absence (e.g., 1 for presence and 0 for absence); (2) categorized, where the matrix contains information that allows for a qualitative identification of different types of offices (e.g., 2 for headquarters, 1 for subsidiaries, 0 for absence); (3) rank-ordered, where the relative importance of the branch in a certain city is reflected in the corresponding matrix value (e.g. the GaWC approach, where offices are ranked according to a 6-point scale, ranging from global headquarters as a 5 to absence as a 0$)^{3}$; and (4) valued, where the relative importance of a branch in a certain city is reflected in the corresponding value (e.g., turnover or asset size). The importance of mentioning these different coding schemes lies, of course, in its implications for the permitted calculations on this (and/or the transformed) datasets. However, the difference between rank-ordered and valued scores are less distinct in practice, because rank-ordered scores are close approximations of genuine measurements of office importance, while robustness assessments suggest different assignments of rank-ordered scores often result in similar general patterns of the corporate network (Liu and Taylor, 2011).

To facilitate our discussion, in what follows we will make use of a sample city-by-firm matrix (Figure 1). This hypothetical matrix describes the distribution of six firms (Firms A-F) across five cities (New York, London, Paris, Tokyo, and Beijing). We use a valued city-by-firm matrix, representing individual offices' importance within the intra-firm network. Following GaWC's often-used empirical model, these office values range from 0 to 5 , where 0 indicates absence of firm, 5 indicates the presence of the firm's headquarters, and the values in-between are a measure of the relative importance of an office in a firm's network. For example, Firm $A$ is headquartered in New York, and has a major office (representing a value of 4) in Paris and a small office (representing a value of 2 ) in Tokyo. The next sections present an overview of what have been the three major ways in which the city-by-firm matrix has been 'readied' for and subsequently used in urban network research.

[FIGURE 1 ABOUT HERE]

City networks formed by ownership linkages 
The first approach essentially draws on an extremely simple projection of the twomode dataset into a one-mode inter-city dataset. That is, urban networks are defined by looking at the ownership linkages running from headquarters to 'other' parts of the firm, as these linkages represent "a direct interaction between the city where the headquarters are located and the city where the subsidiary is owned" (Rozenblat and Pumain, 2007, p. 131; see also Alderson and Beckfield, 2004). As it is often assumed that 'large' firms are more likely to establish branches and thus forming intercity linkages (see, however, Godfrey and Zhou, 1999), researchers working along these lines have usually compiled their city-by-firm matrix based on the geographies of the world's largest multinational corporations, such as the Fortune 500 companies (Alderson and Beckfield, 2004; Alderson et al., 2010), or the largest corporations in Europe (Rozenblat and Pumain, 2007; Wall, 2009).

In this approach, the urban network specification is very straightforward: it results in an asymmetric (from headquarter city to subsidiary city) and valued (number of ownership linkages) inter-city matrix. In the latter matrix, the value of a relationship A-B thus simply represents the number of ownership links running from firms headquartered in city $A$ to subsidiaries in city $B$ (Figure 2). For example, two of the firms ( $A$ and $E$ ) in our dataset are headquartered in New York (with office values of 5 ) and have branches in Tokyo, leading to two links from New York to Tokyo. The Tokyo to New York relation, in turn, is restricted to one link as there is only one firm (D) in our dataset with a headquarter in Tokyo that has a subsidiary in New York. In the inter-city matrix, the rows and columns thus represent the ownership linkages sent and received by corresponding cities, respectively.

\section{[FIGURE 2 ABOUT HERE]}

The resulting one-mode network can then be analyzed with the classical batch of network analysis measures. Alderson and Beckfield (2004), for instance, interpret the total number of ties sent (outdegree) as a city's 'power' in the urban network, while the number of ties received (indegree) is interpreted as the 'prestige' of a city. However, more complex network-analytical tools are also possible (Wall, 2009), including assessments of the geographies within overall connectivity patterns (Rozenblat and Melancon, 2009). Furthermore, although the basic outline is straightforward and easy to interpret, in practice analyses can become quite complicated, as this general approach can be extended in a number of ways. For instance, it is possible to look at multiple levels of ownership, and thus define a city's network centrality at different levels of the corporate hierarchy (Wall and van der Knaap, 2010; Rozenblat and Pumain, 2007).

The major strength of this first approach is that the projection function does not seem to imply a lot of assumptions. This is also explicitly emphasized by researchers working along these lines: Rozenblat and Pumain (2007, p. 131), for instance, argue that the strength of this approach lies in the fact that it does not go "beyond what is strictly supported by the available data." That is, it is assumed that headquartersubsidiary relations are tangible, in contrast to other possible inter-urban relations in firm networks that require far more conjecture. 
Nonetheless, this projection function does often result in a rather 'incomplete' picture of inter-city relations for a number of reasons, most of which are related to the questionable assumption that 'command', 'information', 'knowledge', 'capital' etc. above all flow from headquarter cities to subsidiary cities. This assumption is, for instance, problematic in the face of recent qualitative research on 'the myth of global management' in multinational firms (Jones, 2005; Parnreiter, 2010). This literature emphasizes the heterarchic nature of the organization of multi-locational firms, where complex and ever-changing involvement with other subsidiaries and/or relative autarky is in fact common. In addition, the extreme weight on headquarters functions in this projection function is also at odds with the tendency to separate legal/financial headquarters from operational headquarters (Csomos and Derudder, 2012). It is the former that is being used by Forbes and in most empirical urban network research, while it is the latter that seems to be increasingly relevant. A key example is the takeover of American brewer Anheuser-Busch by Belgo-Brazilian brewer InBev. After the takeover, the 'official' corporate headquarters were retained in Leuven (Belgium) as a sign of respect for "the heritage, the source, the romance" of brewing (Modern Brewery Age, 2009), but the de facto functional global management office is now located in Manhattan, New York (http://www.abinbev.com/contact.cfm). It is clear that such hybridity, fuelled by all sorts of constructions to locate legal headquarters in a 'tax-optimizing locations' has an enormous impact on studies that take headquarter-subsidiary relations as being of key importance (see also Ambos and Reitsperger, 2004).

\section{The Interlocking Network Model}

The second approach in this literature is Taylor's (2001) interlocking network model. Although initially designed as part of the broader GaWC research agenda on WCN formation, this method has become one of the 'de facto methods' for measuring and analyzing urban networks (Neal, 2012). It has, for instance, been applied beyond its initial remit of producer services firms (Taylor et al. 2002) to analyze the urban networks formed by Islamic financial services (Bassens et al., 2010), NGOs (Taylor, 2005), and media firms (Hoyler and Watson, 2010). In addition, it has been applied at other scales, for instance to analyze the spatial organization of polycentric megacity regions in Northwest Europe (Hall and Pain, 2006; Taylor et al., 2012), banking networks in Brazil (Rossi and Taylor, 2005), as well as capital control in individual cities (Musil, 2009).

The interlocking city network model is similar to the ownership linkage approach in that is essentially a projection of the two-mode dataset into a one-mode city-to-city matrix. However, the approach is nonetheless very different, not in the least because of its initial focus on service firms. Taylor (2004) states that transnational service firms maintain offices in many different cities throughout the world to provide clients with a superior, global service, and to project a global image. When two cities are home to offices of the same firm, then, it its possible that they are interconnected. The latter is implicitly interpreted as a probability of certain level of 
linkage quality in an interaction model, i.e., as the level of service one can (likely) expect in a firm's network when making connections from city A to city B. Following this logic, the interlocking network approach defines two cities as linked in the network to the extent that (1) they are home to offices of the same firms and (2) the offices in both cities have sizable functions/capabilities. In practice, the inter-city matrix is simply calculated by multiplying the city-by-firm matrix with its transpose.

This model is operationalized through collecting data on the office networks of service firms (or other actors, depending on the purpose of the analysis). These data are readily available on firms' websites where they promote their 'global' status as a means of both impressing clients in a competitive services market and recruiting graduates in a competitive jobs market (Taylor et al., 2012). With $n$ firms and $m$ cities, this data collection creates an $n$ firms $x m$ city-by-firm service values matrix as in our sample dataset with each cell reflecting a city's importance in the office network of a firm. Applying the interlocking network model gives an estimate of the flows of information, knowledge, capital, etc. between cities.

In our example, the projected inter-city matrix is presented in Figure 3 . For the Beijing-Tokyo relation, for instance, we obtain a linkage of $=2 \times 0+3 \times 0+3 \times 1+3 \times 5+$ $1 \times 0+1 \times 4=22$. It is clear that the resulting urban network is very dense (with a network density equal to 1 , with all cities being inter-connected) and rather 'flat' (London, the most connected city, is only $50 \%$ more connected than Beijing, the least connected city). Gini coefficients are employed to assess the distribution of connectedness among cities across different models (Table 1), and the urban network produced by the interlocking network is indeed the "flattest", i.e. it has smallest Gini coefficient. This can of course be traced back to the assumption that every office is connected to every other office other, whereas in the ownership linkage approach only headquarter-to-subsidiary linkages are counted in the ownership linkage. A key consequence is that the extreme 'skewness' observed in the latter approach is not reproduced in the interlocking network model approach: a much larger number of cities is considered as being 'active' in the network, which in turn explains some of the profound differences between the results in Taylor et al. (2002) and Alderson and Beckfield (2004).

\section{[TABLE 1 ABOUT HERE]}

The merit of the interlocking network model lies exactly in this great variety of connections that emerge. Although Rozenblat and Pumain (2007) make the case for the ownership linkage approach because it entails 'few assumptions', Taylor's (2004) assumptions are not necessarily far-reaching or very unlikely: he basically assumes that (1) offices in the networks of service firms generate more flows within their network than to other firms in their sector, which is inherently plausible in a context where protecting global brand image through providing seamless service is the norm; and that (2) the more important the offices located in two cities, the more flows will be generated between them. It is not clear why these assumptions should be less unlikely than the one in the ownership linkage approach, and the richer and 
more complex inter-city network that emerges quite possibly paints a more nuanced picture of inter-city connectivity under conditions of contemporary globalization.

However, the relatively 'flatter' and empirically richer inter-city network emerging out of this projection is perhaps also the model's Achilles heel. In standard network analysis, Figure 4 represents a fully connected network (or a so-called 'clique', see Derudder and Taylor, 2005), while Beijing is in practice only connected to Paris via a single Firm C. In fact, as soon as there is a firm that has a presence in all cities (Firm C in our case), the interlocking city network will generate a fully connected city-to-city matrix (Neal, 2012). More generally, then, this particular one-mode projection inflates the number of linkages in the network to the point where it generates a very dense city connectivity matrix that is hard to handle with network analysis techniques (Latapy et al., 2008). Furthermore, this 'inflated' connectivity can bias the analytical results, as it becomes difficult to distinguish between 'actual' clusters of densely connected cities in the city network from those emanating from the projection function (Neal, 2012). Thus Derudder and Taylor (2005) had to resort to using filters and thresholds before an actual analysis of 'cliques' become possible, which entails al sorts of new interpretation problems (see also Neal, 2008).

\section{City Networks as Two-mode City-by-firm Networks}

The first two approaches share one further common drawback, related to the transformation of the two-mode data into a one-mode dataset. That is, projection of two-mode data into one-mode network almost inevitably means lead to a loss of information because certain network structures disappear after the projection (Latapy et al., 2008; Wang et al., 2009), such as cities and firms that are linked through multiple intermediate firms (Neal, 2008), and cities/firms with only one linkage (Wang et al., 2009). In our case, for instance, we would not identify Firm C's strategic position in linking Beijing and Paris from the first two approaches.

This is a well-known problem in network analysis that has long been ignored in the corporate organization approach to studying urban networks, quite probably because researchers' prime interest lies with the cities rather than the network analysis per se. As a corollary, with few exceptions (for example, Mould and Joel, 2010), urban network research has long ignored the alternatives that have been devised in the network analysis literature, which basically consists of a set of twomode network analytics. The major advantage of two-mode network analytics lies in the fact that it does not collapse or transform the original city-by-firm dataset, and preserves all the information that was initially collected ${ }^{4}$.

\footnotetext{
${ }^{4}$ Despite the fact that several empirical studies have explored the city-by-firm matrix in full (Taylor et al., 2002), these studies are not included in our discussion as they treat city-by-firm matrices as non-relational multivariate datasets, where cities are observation units, and firms represent different variables. In analyzing these multivariate datasets, cities are treated as independent samples, and no assumption is made about the urban system.
} 
In the two-mode approach, cities are consistently studied in the context of the cityby-firm relationship. In a two-mode corporate network, cities are linked by hosting branches of the same firm, whereby firms are connected by co-locating in the same city. On the one hand, similar to the rationale underlying the first two approaches, cities co-hosting the same firms are connected through intra-firm networks. On the other hand, urban-economic literatures (e.g., Baldwin et al., 2008) suggest that firms agglomerating in the same cities are more probable to be associated through both tangible (e.g., competition and alliance) and intangible ways (e.g., labor pooling and technological spillovers). In other words, the more cities in which two firms colocate, the greater the possibility that these two firms are somehow "inter-linked" (Neal, 2008).

The linkages in the two-mode network involve both cities and firms, making it possible to assess cities' and firms' positions in the corporate network simultaneously. Similar to previous approaches, the two-mode network model can produce a ranking of cities' degree connectivity ${ }^{5}$ : In our example, New York is the most connected city, as it hosts branches of all six firms and garners a total service value of 19 (Figure 4). In addition to the city ranking, firms' positions in the network can also be evaluated: Firm $C$ is the most active firm in terms of pursing global coverage, with branches in all five cities. Firms $A$ and $E$, with three branches, have comparatively less expanded their office networks.

\section{[FIGURE 4 ABOUT HERE]}

Taking both cities and firms into consideration, a two-mode network perspective allows us to explicitly model how locational strategies of individual firms interact and aggregate into the corporate network (Liu et al., 2012). The aggregation of locational strategies of individual firms often generates repeating micro-level network patterns, which consist of a subset of cities and firms. These micro-level structures are indicative of the underlying network formation process. For example, a "star" structure in the two-mode network (e.g., "NY" in Figure 4), such as one city hosting many firms may imply a preferential attachment process: firms establishing a new branch "attach" themselves to cities with significant amount of similar or related firms to exploit economies of agglomeration (Baldwin et al., 2008) - a "star" structure represent the interdependence and cumulative effects in the formation of office networks. Formal statistical analyses can be applied to the two-mode network data to quantify the impact of such network structures, simulate individual cities and firms' behavior of forming linkages, test alternative hypotheses about network formation (Wang et al. 2009; Snijders et al. 2010). However, the rationale and implementation of these techniques are out of the scope of this review.

\footnotetext{
${ }^{5}$ The degree connectivity of cities in the network is calculated as the number of firms individual cities host, and the degree of firms is computed as the number of cities that individual firms locate in. The number of cities/firms can also be valued/weighted to represent the importance of individual offices, i.e., service values in our example.
} 
Importantly, the two-mode approach is essentially compatible with and provides a potential over-arching framework for the first two approaches. Conventional onemode networks focusing on cities and firms separately (e.g., a one-mode network that counts the number of flights among cities, or a one-mode network that encodes whether firms are allied with each other) can be connected with the two-mode intercity corporate network via common nodes (i.e., cities or firms), and integrated to synthesize the interaction and co-evolution of multiple networks (Pflieger and Rozenblat, 2010; Liu, 2012). For example, advancement in statistical network models (Snijders et al., 2010) have allowed us to examine how the strategic alliance network among firms affect their locational strategies and consequently change the intercity corporate network, which in turn influence the telecommunication and transportation connections among cities.

Although the two-mode network approach is arguably the most promising approach for analyzing urban networks through corporate networks, the model does have some drawbacks. First, to date two-mode network analytics are rather limited, not in the least because of the complexity of the approach and the associated computational burden. For example, blockmodelling techniques, which group cities and firms into densely connected groups or "blocks" (and which have been fruitfully applied in a one-mode intercity network, see Alderson and Beckfield, 2004), are quite slow for two-mode networks. Second, the interpretation of results of twomode network analysis is less intuitive, and may therefore be less attractive for urban scholars. Nevertheless, these issues are likely to be alleviated with the advancement of two-mode network analytics (Wang et al. 2009; Snijders et al. 2010).

\section{Conclusions and the way forward}

This paper has reviewed the three major empirical models for approximating urban networks through an analysis of corporate networks: the ownership linkage model, the interlocking network model, and the two-mode network model. Despite different underlying assumptions and operationalizations, all three models build on the city-by-firm datasets to estimate how individual cities are connected through corporate networks.

The ownership linkage model focuses on the headquarter-subsidiary relationship in corporate networks, and provides a straightforward transformation from the city-byfirm relationship to city-to-city 'commanding' linkages. However, the ownership linkage model often produces a rather 'incomplete' and hierarchical landscape of urban networks, as it neglects the heterarchical nature of the organization of multilocational firms.

The interlocking network model, in turn, accounts for this heterachical nature and generates a 'flatter' and empirically richer inter-city network. Nevertheless, the network projection method employed by this approach 'inflates' network connectivity, making it difficult to distinguish between 'actual' clusters of densely 
connected cities in the city network from those emanating from the projection function.

Unlike the previous two approaches, the two-mode network model does not cause loss of information through network projection, and utilizes the full city-by-firm dataset to evaluate firms and cities' positions in corporate networks simultaneously. However, it would seem that urban scholars are deterred from using two-mode network analyses as these are often complicated and computational-intensive, sometimes yielding less intuitive analytical results.

Considering the pros and cons of individual models leads us to three further points of attention in this literature. First, there seems to be a need to exploit the interchangeability of different approaches and model the same set of city-by-firm data with multiple empirical models. The interchangeability refers to the fact that all three models build on the same type of city-by-firm dataset. Each empirical model will create an "urban network" that will in turn be explored with a variety of analytical procedures, and we suggest to model the same set of city-by-firm data with different models and synthesize the analytical results. This also helps us to alleviate the issues of structurally determined results that may arise from the technicality of individual models (Neal, 2012).

Second, and related to the previous point, there seems to be an overarching need to implement calibration needs to be to allow for falsifiability of the modeling results. Lack of calibration has become one major drawback of approximating urban connections through corporate networks, as the empirical models discussed in this paper provide estimates rather than observations of real-world corporate activities (Derudder and Witlox, 2008). Existing studies have benchmarked estimated corporate networks with measured physical intercity networks, such as Internet, telecommunication, and airline networks (Choi et al., 2006; Taylor et al., 2007). However, genuine measurements about intra-firm activities (e.g., telephone calls/emails/transactions among individual branches) are needed for more accurate calibration (MIT Senseable City Lab, 2012).

And third and finally, the two-mode network model opens up the interesting possibility of modeling both cities and firms simultaneously. Cities and firms often form local network structures, which emerge repeatedly in corporate networks and are indicators of the underlying network formation and interdependence (Robins et al., 2007). With two-mode network models, we could capture the interaction among cities and firms, synthesize multiple networks, and test urban network formation hypotheses, deepening our understanding about how individual cities and firms interact locally and form observed global corporate networks. 


\section{Figures}

Figure 1. Pedagogical city-by-firm matrix ((New York (NY), London (LN), Paris (PA), Tokyo (TK), and Beijing (BJ))

\begin{tabular}{lllllll}
\hline & A & B & C & D & E & F \\
\cline { 2 - 7 } NY & 5 & 2 & 3 & 2 & 5 & 2 \\
LN & 0 & 5 & 4 & 2 & 3 & 5 \\
PA & 4 & 4 & 5 & 0 & 0 & 0 \\
TK & 2 & 3 & 1 & 5 & 1 & 1 \\
BJ & 0 & 0 & 3 & 3 & 0 & 4 \\
\hline
\end{tabular}


Figure 2. Generation of ownership linkages (a) Original city-by-firm relationship; (b) transformed ownership linkages; (c) graphical representation of ownership linkages

\begin{tabular}{lllllll}
\multicolumn{1}{l}{ (a) } & \multicolumn{1}{c}{} & & & & & \\
\hline \multicolumn{1}{c}{} & A & B & C & D & E & F \\
\cline { 2 - 7 } NY & 5 & 2 & 3 & 2 & 5 & 2 \\
LN & 0 & 5 & 4 & 2 & 3 & 5 \\
PA & 4 & 4 & 5 & 0 & 0 & 0 \\
TK & 2 & 3 & 1 & 5 & 1 & 1 \\
BJ & 0 & 0 & 3 & 3 & 0 & 4 \\
\hline
\end{tabular}

(b)

\begin{tabular}{l|lllll|l}
\hline \multicolumn{1}{c}{} & NY & LN & PA & TK & \multicolumn{1}{l}{ BJ } & OD \\
\cline { 2 - 6 } NY & 0 & 1 & 1 & 2 & 0 & 4 \\
LN & 2 & 0 & 1 & 2 & 1 & 6 \\
PA & 1 & 1 & 0 & 1 & 1 & 4 \\
TK & 1 & 1 & 0 & 0 & 1 & 3 \\
BJ & 0 & 0 & 0 & 0 & 0 & 0 \\
ID & 4 & 3 & 2 & 5 & 3 & \\
\hline
\end{tabular}

$O D=$ Outdegree, the number of ownership linkages individual cities send ID = Indegree, the number of ownership linkages individual cities receive.

(c)

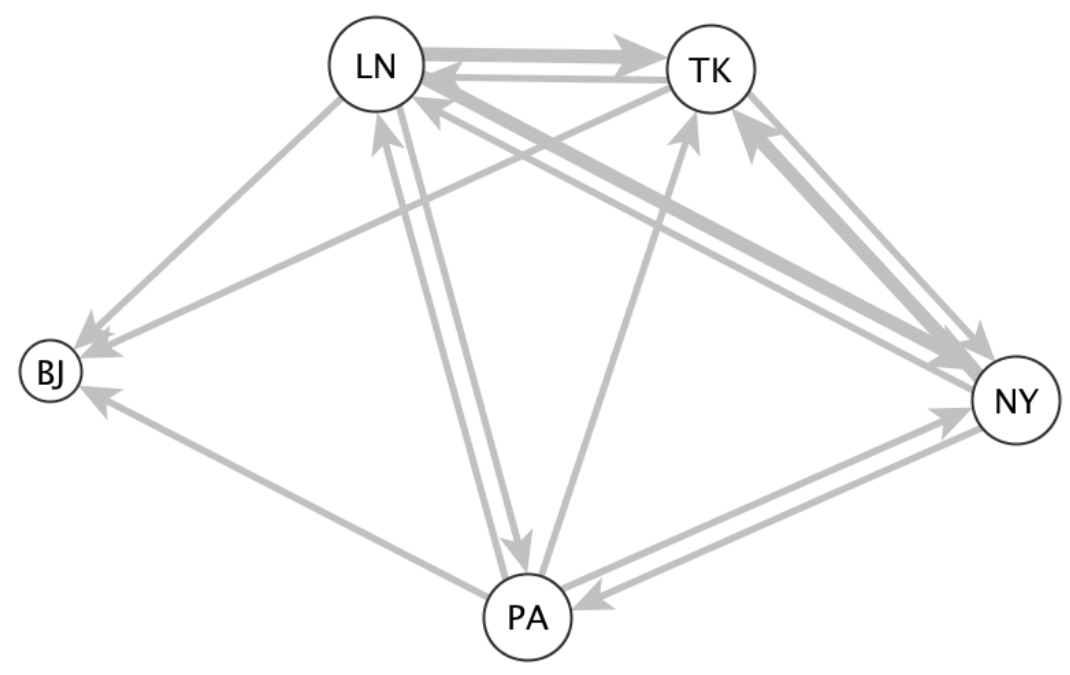

Link width is proportional to the number of headquarter-subsidiary linkages, and the nodal size is proportional to cities' total outdegree and indegree. 
Figure 3. (a) inferred Interlocking city network (diagonal elements are set to zero) and (b) its graphical representation.

(a)

\begin{tabular}{l|llllll}
\hline \multicolumn{1}{c}{} & NY & LN & PA & TK & BJ & GNC \\
\cline { 2 - 7 } NY & 0 & 51 & 43 & 36 & 23 & 153 \\
LN & 51 & 0 & 40 & 37 & 38 & 166 \\
PA & 43 & 40 & 0 & 25 & 15 & 123 \\
TK & 36 & 37 & 25 & 0 & 22 & 120 \\
BJ & 23 & 38 & 15 & 22 & 0 & 98 \\
GNC & 153 & 166 & 123 & 120 & 98 & \\
\hline
\end{tabular}

GNC = Global Network Connectivity (Taylor 2001), the total number of linkages of individual cities.

(b)

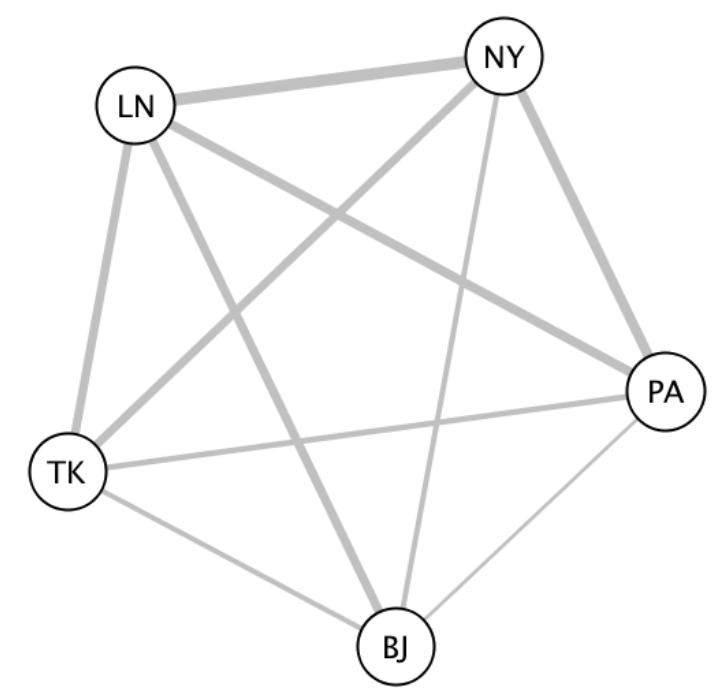

Link width is proportional to the number of linkages, and the nodal size is proportional to cities' total outdegree and indegree. 
Figure 4. (a) Degree centralities in the two-mode network and (b) its graphical representation.

\begin{tabular}{lllllllll}
\hline Rank & Cities & $\begin{array}{l}\text { Binary- } \\
\text { Degree }\end{array}$ & Cities & $\begin{array}{l}\text { Valued- } \\
\text { Degree }\end{array}$ & Firms & $\begin{array}{l}\text { Binay- } \\
\text { Degree }\end{array}$ & Firms & $\begin{array}{l}\text { Valued- } \\
\text { Degree }\end{array}$ \\
\hline $\mathbf{1}$ & NY & 6 & NY & 19 & C & 5 & C & 16 \\
$\mathbf{2}$ & TK & 6 & LN & 19 & B & 4 & B & 14 \\
$\mathbf{3}$ & LN & 5 & PA & 13 & D & 4 & D & 12 \\
$\mathbf{4}$ & PA & 3 & TK & 13 & F & 4 & F & 12 \\
$\mathbf{5}$ & BJ & 3 & BJ & 10 & A & 3 & A & 11 \\
$\mathbf{6}$ & & & & & E & 3 & E & 9 \\
\hline
\end{tabular}

(b)

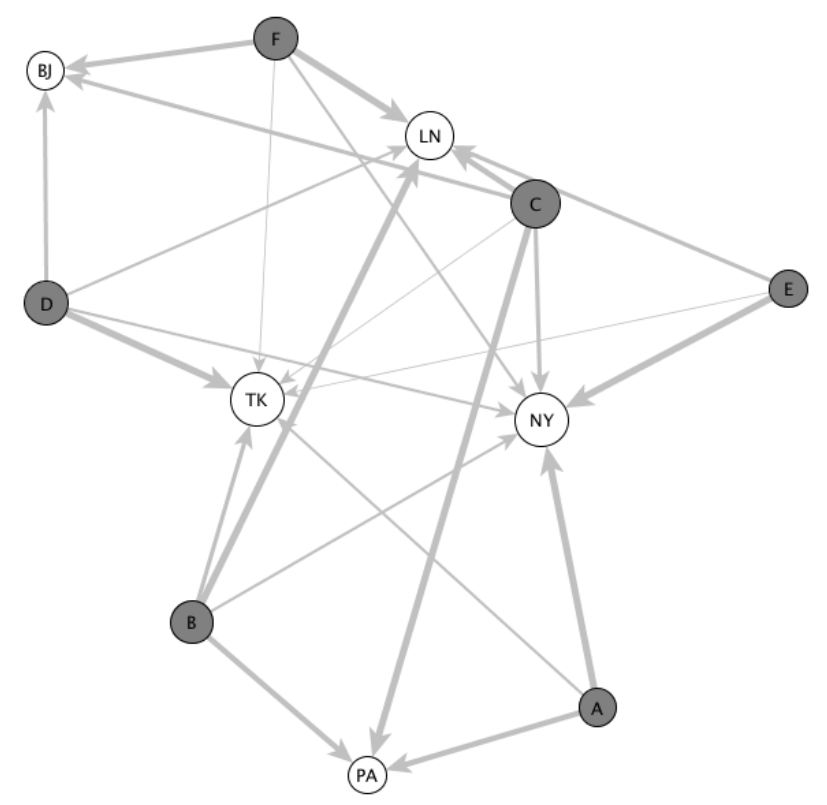

While and grey circles represent cities and firms, respectively. Link width is proportional to the number (total value) of linkages, and the nodal size is proportional to cities' total outdegree and indegree. 
Table 1. Inequality among cities' connectedness in different models

\begin{tabular}{|c|c|c|c|}
\hline & \multicolumn{2}{|c|}{ Ownership } & \\
\hline Measurements & OD & ID & Degree \\
\hline Gini & 0.3059 & 0.1647 & 0.1024 \\
\hline
\end{tabular}

Larger Gini coefficient represents greater inequality among cities' connectedness. A zero Gini coefficient indicates total equality, whereas a value of one suggests extreme inequality. 


\section{References}

Alderson, A and Beckfield, J (2004) Power and position in the world city system. American Journal of Sociology 109, 811-851.

Alderson, A, Beckfield, J and Sprague-Jones, J (2010) Intercity relations and globalization: The evolution of the global urban hierarchy, 1981-2007. Urban Studies 47, 1899-1923.

Ambos, B and Reitsperger, W (2004) Offshore centers of excellence: Social control and success. MIR: Management International Review 44, 51-65.

Baldwin, J, Beckstead, D, Brown, W and Rigby, D (2008) Agglomeration and the geography of localization economies in Canada. Regional Studies 42, 117-132.

Bassens, D, Derudder, B and Witlox, F (2010) Searching for the Mecca of finance: Islamic financial services and the world city network. Area 42, 35-46.

Beaverstock, JV, Doel, MA, Hubbard, PJ and Taylor P (2002) Attending to the world: competition, cooperation and connectivity in the World City network. Global Networks 2, 111-132.

Borgatti, SP and Everett MG (1997) Network analysis of 2-mode data. Social Networks 19, 243-269.

Camagni, R (1993) From city hierarchy to city network: Reflections about an emerging paradigm. in Lakshmanan, TR and Nijkamp, P (Eds), Structural and Change in the Space Economy. Springer-Verlag, Berlin, pp. 66-87.

Castells, M (2001) The Rise of Network Society, $2^{\text {nd }}$ edn. Oxford: Blackwell.

Choi, J, Barnett, G and Chon, B (2006) Comparing world city networks: a network analysis of Internet backbone and air transport intercity linkages. Global Networks 6 , 81-99.

Csomos, G and Derudder, B. (2012) European cities as command and control centres, 2006-11. European Urban and Regional Studies, in press.

Derudder, B and Taylor, P (2005) The cliquishness of world cities. Global Networks 5, 71-91.

Derudder, B (2006) On conceptual confusion in empirical analyses of a transnational urban network. Urban Studies 43, 2027-2046.

Friedland, R, Palmer, D and Stenbeck, M (1990) The geography of corporate production: Urban, industrial, and organizational systems. Sociological Forum 5 , 335-359. 
Goddard, J and Smith, I (1978) Changes in corporate control in the British urban system, 1972-1977. Environment and Planning A 10, 1073-1084.

Godfrey, B, and Zhou, Y (1999) Ranking world cities: multinational corporations and the global urban hierarchy. Urban Studies 20, 268-281.

Hall, P and Pain, K (2006) The Polycentric Metropolis: Learning from the Mega-city Regions in Europe. Earthscan: London.

Holton, RJ (2008) Global Networks. New York: Palgrave Macmillan.

Hoyler, M and Watson A. Global media cities in transnational media networks. GaWC research bulletin. http://www.lboro.ac.uk/gawc/rb/rb358.html last accessed May 15, 2012.

Jacobs, JM (2011) Urban geographies I: Still thinking cities relationally. Progress in Human Geography 36, 412-422.

Jones, A (2005) Truly global corporations? Theorizing 'organizational globalization' in advanced business-services. Journal of Economic Geography 5, 177-200.

Latapy, M, Megnien, C and Del Vecchio, N (2008) Basic notions for the analysis of large two-mode networks. Social Networks 30, 31-48.

Liu, X and Taylor, P (2011) A robustness assessment of GAWC global network connectivity ranking. Urban Geography 32, 1227-37.

Liu, X and Derudder, B (2012) Two-mode networks and the interlocking world city network model: A reply to Neal. Geographical Analysis 44, 171-173.

Liu, X, Derudder, B, Liu, Y, Witlox, F and Shen, W (2012) A stochastic actor-based modelling of the evolution of an intercity corporate network. Environment and Planning $A$, accepted.

Liu, X (2012) Exploring joint dynamics of intercity Internet and corporate networks: A stochastic actor-based modeling approach. Global Networks, conditionally accepted.

Massey, D and Collective (1999) Issues and debates in Massey, D, Allen, J and Sarre, P (Eds), Human Geography Today. Polity, Cambridge, pp. 3-21.

Michelson, R, and Wheeler, J (1994) The flow of information in a global economy: the role of the American urban system in 1990. Annals of Association of American Geographers 84, 87-107.

MIT Senseable City Lab (2012) Spring spree: Spending patterns in Spain during Easter 2011. http://senseable.mit.edu/bbva/ last accessed on May 15, 2012. 
Mould, O and Joel, S (2010) Knowledge networks of 'buzz' in London's advertising industry: A social network analysis approach. Area 42, 281-292.

Musil, R (2009) Global capital control and city hierarchies: an attempt to reposition Vienna in a world city network. Cities 26, 255-265.

Neal, Z (2008) The duality of world cities and firms: Comparing networks, hierarchies, and inequalities in the global economy. Global Networks 8, 94-115.

Neal, Z (2011) Differentiating centrality and power in the world city network. Urban Studies 48, 2735-2750.

Neal, Z (2012) Structural determinism in the interlocking world city network, Geographical Analysis 44, 162-170.

Nordlund, C (2004) A critical comment on the Taylor approach for measuring world city interlocking linkages. Geographical Analysis 36, 290-296.

Parnreiter, C (2010) Global cities in Global Commodity Chains: exploring the role of Mexico City in the geography of global economic governance. Global Networks 10, 35-53.

Pflieger, G and Rozenblat, C (2010) Urban networks and network theory: The city as the connector of multiple networks. Urban Studies 47, 2723-2735

Pred, A (1977) City-Systems in Advanced Economies. London: Hutchinson.

Rossi, E and Taylor, P (2005) Banking networks across Brazilian cities: Interlocking cities within and beyond Brazil. Cities 22, 381-393

Rozenblat, $C$ and Pumain, D (2007) Firm linkages, innovation and the evolution of urban systems, in Taylor, P, Derudder, B, Saey, P and Witlox, F (Eds) Cities in Globalization: Practices, Policies, Theories. Routledge, London, pp. 130-156.

Rozenblat, C and Melancon, G (2009) A small world perspective on urban systems, in Bavaud, F and Mager, C (Eds), Handbook of Theoretical and Quantitative Geography, pp. 431-457. UNIL, Lausanne.

Sassen, S. (2001) The Global City, 2nd edn. Princeton, NJ: Princeton University Press.

Snijders, TAB, Van de Bunt, GG and Steglichc, CEG (2010) Introduction to stochastic actor-based models for network dynamics. Social Networks 32, 44-60

Taaffe, EJ (1962) The urban hierarchy: an air passenger definition. Economic Geography 38, 1-14. 
Taylor, P (1997) Hierarchical tendencies amongst world cities: a global research proposal. Cities 14, 323-332

Taylor, P (2001) Specification of the world city network. Geographical Analysis 33, 181-194.

Taylor, P (2004) World City Network: A Global Urban Analysis. London: Routledge.

Taylor, P (2005) Leading world cities: empirical evaluations of urban nodes in multiple networks. Urban Studies 42, 1593-1608.

Taylor, P, Walker, D, Catalano, G and Hoyler, M (2002) Diversity and power in the world city network. Cities 19, 231-241

Taylor, P, Derudder, B and Witlox, F (2007) Comparing airline passenger destination with global service connectivities: A worldwide empirical study of 214 cities. Urban Geography 28, 232-248.

Taylor, P, Evans, D, Hoyler, M, Derudder, B and Pain, K (2009) The UK space economy as practised by advanced producer service firms: Identifying two distinctive polycentric city-regional processes in contemporary Britain. International Journal of Urban and Regional Research 33, 700-718.

Taylor, P, Derudder, B, Hoyler, M and Ni, P (2012) New regional geographies of the world as practised by leading advanced producer service firms in 2010. GaWC research bulletin. http://www.lboro.ac.uk/gawc/rb/rb392.html, last accessed May 15, 2012.

Taylor, P, Csomos, G (2012) Cities as control and command centres: Analysis and interpretation. Cities, in press. doi:10.1016/j.cities.2011.09.005

Tonts, M and Taylor, M (2011) Corporate location, concentration and performance: Large company headquarters in the Australian urban system/ Urban Studies 47, 2641-2664.

Wall, R (2009) Netscape: Cities and Global Corporate Networks. PhD diss., Erasmus Research Institute of Management (ERIM).

Wall, R and van der Knaap, G (2011) Sectoral differentiation and network structure within contemporary worldwide corporate networks. Economic Geography 87, 267308.

Wang P, Sharpe K, Robins G, Pattison P (2009). Exponential random graph $\left(\mathrm{p}^{*}\right)$ models for affiliation networks. Social Networks, 31(1), 12-25. 
Yates, R (1997) The city-state in ancient China, in Nicholas, D and Charlton, T (Eds), The Archaeology of City-States: Cross-cultural Approach. Washington, DC:

Smithsonian Institution Press. 